\title{
Assessment of Postnatal Care Service Utilization and Associated Factors among Mothers Attending Antinatal Care at Ambo Health Facilities
}

\section{Moreda TB* and Gebisa K}

Department of Public Health, College of Medicine \& Health Sciences, Ambo University, Ambo, Ethiopia

*Corresponding author: Tilahun Bogale Moreda, Associate Professor at department of Public

Research Article

Volume 2 Issue 2

Received Date: August 03, 2018

Published Date: August 18, 2018 Health, College of Medicine \& Health Sciences, Ambo University, Ambo, Ethiopia, Email: mikiasbo12@gmail.com

\section{Abstract}

Background: In Ethiopia, maternal health service utilization is very low, especially postnatal care (PNC). The percentage of mothers who receive care within two days of childbirth has shown little progress, from $2.4 \%$ in 2000 to $13 \%$ in 2014 . However, it is very far below the expected level as compared to other sub-Saharan regions. Therefore, the aim of this study was to assess PNC services utilization.

Objectives: To assess the knowledge, attitude and Practice on PNC utilization and associated risk factors among mothers attending ANC at Ambo and Awaro Health Centers.

Methods: Facility based cross- sectional study was conducted from November 2017 to January 2018. A total of 323 study subjects were selected by simple random sampling technique from mothers of child bearing age (15-49) who were attending Ambo and Awaro Health Centers for ANC and PNC follow up. Data were collected by using structured questionnaires through face to face interviews. The data were analyzed using SPSS.

Results: Results of this study revealed that majority of mothers were sought ANC visit during their recent pregnancy and $82.4 \%$ of the respondents were delivered at health facilities. However, $63.5 \%$ of women did not receive PNC services. The most frequent reasons for not obtaining PNC services were due to lack of awareness, apparently healthy and shortage of money. The following factors were identified as having important predictors in the utilization of PNC services Husband's occupation, number of ANC visit, and decision making power of the mother were statistically significant associations with the utilization of PNC service. Another important reason indicated by participants was lack of willingness and unfriendly approach by some health professionals in government health facilities hinder mothers from utilization of PNC services.

Conclusion and Recommendation: Husband's occupation, number of ANC visit, and decision making power of the mother were statistically significant factors with the utilization of PNC service. This study revealed that utilization of PNC in Ambo town is low compared to other previously conducted studies in Ethiopia. Therefore, to increase utilization of PNC coverage and reduce maternal and neonatal mortality mothers should obtain more adequate education, awareness to wards to importance of PNC services, ANC and delivery.

Keywords: PNC; ANC; Knowledge; Attitude and Practice; Mothers 


\section{Introduction}

Postnatal care is the care given just after delivery and through six weeks of life and is recognized as a critical time for both mother and the baby. Postnatal care is one of the most important maternal health- care services for not only prevention of complications of impairment and disabilities but also reduction of maternal mortality $[1,2]$.

Postnatal care services enable the health professionals to identify post-delivery problems, including potential complications and prompt treatments as well as promoting health of the mother and baby. Postnatal care seeks to improve maternal, newborn and infant receiving essential postpartum, newborn care and family planning services $[3,4]$.

According to WHO (2006) the elements of postnatal care are prevention of complication of mother and baby including vertical transmission of diseases from mother to baby, early detection and treatment of problems and complication readiness, provision of care to mother and baby by skilled attendant, assisting the mother and her family to evaluate and develop personalized postnatal care plan, counseling for HIV and testing, counseling for contraception (birth spacing) and resumption of sexual activity, health promotion using health messages and counseling, referral of mother and baby for special care when necessary [4].

Regular prenatal visits can help your doctor monitor your pregnancy and identify any problems or complications before they become serious. Babies born to mothers who lack prenatal care have tripled the chance of being born at a low birth weight. New born with low birth weights are five times more likely to die than those whose mothers received prenatal care [5].

Prenatal care ideally starts at least three months before you begin trying to conceive. Globally, there were an estimated 289000 maternal deaths from complications related to pregnancy and childbirth which is a decline of $45 \%$ from 1990. Majority of the maternal deaths occur in developing regions. Among the developing regions the subSaharan Africa region alone accounted for 62\% (179 000) of global deaths followed by Southern Asia at 24\% (69 000). The global maternal mortality ratio (MMR) in 2013 was 210 maternal deaths per 100000 live births, down from 380 maternal deaths per 100000 live births in 1990 [6,7]. The MMR in developing regions (230) was 14 times higher than in developed regions. Sub-Saharan Africa has the highest regional MMR (510) per 100,000 live births. MMR in Ethiopia is also among the highest in the World [6]. According to the World Health Organization 2012 report, 9000 maternal deaths occurred in Ethiopia in 2010. According to the annual performance report of HSDP IV (2013/2014) referring to the Ethiopian Mini Demographic Health Survey (EMDHS) 2014: Antenatal care (ANC) was $97.4 \%$ in the year 2013 and $98.1 \%$ in the year 2014 [6].

Postnatal care (PNC) was 50.5\% in the year 2013 and $66.2 \%$ in 2014 , Deliveries attended by skilled personnel was $23.1 \%$ in the year 2013 and is $40.9 \%$ in 2014, Clean and safe delivery by Health extension worker (HEW) was $11.6 \%$ in the year 2013 and was $8.8 \%$ in the year 2014, Contraceptive acceptance rate (CAR) was 59.5\% in the year 2013 and was 63.01\% in the year 2014 and Prevention of Mother- to - Child Transmission of HIV (PMTCT ) was 54.9\% in the year 2013 and $57 \%$ in 2014 Pregnant women on ART was $42.9 \%$ in the year 2013 and $60.6 \%$ in 2014. Contraceptive prevalence rate (CPR) has increased from $28.6 \%$ in 2011 to $41.8 \%$ in 2014 , Total fertility rate (TFR) has reduced from 4.8 in 2011 to 4.1 in 2014 [6]. Skilled birth attendance has increased from $10 \%$ to $14.5 \%$.The report notes that significant developments have been registered from 2013 to 2014 in maternal health care. However, maternal mortality remains dismally high $[7,8]$. Ambo and Awaro health Centers is also no exceptional from these situations. We were limited information about the current utilization of postnatal care service in the study area. Previously no research was conducted in the study area regarding PNC services utilization and associated factors. Therefore it will be expect that, the results of this study were help as an important input for any possible intervention aim at improved the PNC service utilization.

\section{Method and Materials}

\section{Study area}

The study was conducted in Ambo town which is located at distance of $114 \mathrm{~km}$ west of Addis Ababa, the capital city of Ethiopia, in Oromia Regional State, West Shewa Zone. Ambo is among a few privileged towns of its time to have its own municipal administration since 1931, and a master plan since 1983. It covers a total area of 1320 hectares. The town is serving as an administrative, commercial and transport center of the West Shewa Zone. Based on figures from the Central Statistical Agency (CSA) in 2007 report, total population of Ambo town 42,550 from this $21700(51 \%)$ were males and 20,850(49\%) were females. Ambo town constitutes 4 kebeles in those kebeles there are 
2 HC, 1General Hospital, 1Referal Hospital, and $~ 20$ Private clinics.

Ambo Health center was established in 1996E.C. It serves 43,222 populations. The health center has a total of 45 employees, 5 Health officers, 2 BSC Nurse ,5 Clinical Nurses , 3 midwifery, 2 lab technician, 2 Pharmacist, 14 Supportive Staffs, 12 HEWs, where as Awaro Health center was established in 2003 E.C. It serves 39,831populations. The health center has a total of 49 employees, 4 Health officers, 4 BSC Nurse ,6 Clinical Nurses , 2 midwifery , 2 lab technician, 2 Pharmacist, 16 Supportive Staffs, 13 HEWs. The study was conducted at gynecology/obstetrics ward, from November 2017 to January 2018.

To determine the sample size a single population proportion formula was used. Assuming that 25.8\% of urban and rural women using postnatal care service based on a similar study done and with further assumption of 95\% confidence level, 5\% margin of error, and 10\% non respondent rate, a total sample of 323 study subjects were required.

Structured questionnaire was used to collect the data. The questionnaire was developed after review of available scientific literatures (51). It has two parts: Socio-demographic characteristics and Maternal History. First the questioner were prepared in English language; and then translated in to Afan Oromo and Amharic versions which are local languages and back to English again in order to maintain the instrument validity or to check the consistency of the questioner. Six data collectors and one supervisor who were public health students from Ambo University, department of Public health were recruited. For data collectors and supervisors, a one day intensive training was given before the pretest had been undertaken. The supervisor and principal investigator had closely followed the day-to-day data collection process and ensure completeness and consistency daily. Structured and pretested questionnaires were utilized to collect the data from the respondents by face to face interview.

Pre-test of questionnaire for the clarity and consistency of questions and training of data collectors were done to avoid information contamination. Then, necessary corrections were made based on the feedback of the data collectors.

The statistical analysis was done using SPSS software version 20.0. After the data entry, it was edited and cleaned before analysis. Frequency, percentage and descriptive summaries were utilized to explain the study variables.

Ethical clearance was obtained from Ambo University, College of Medicine and Health Sciences Institutional Review Board. Supportive letter was taken to Ambo and Awaro Health centers and District health office. Informed verbal consent was obtained from each respondent.

\section{Result}

From a total of 323 mothers interviewed, all of them responded to the questionnaires making the response rate $100 \%$. The majority of the mothers̀ age $25-29$ years $129(39.9 \%)$ followed by $100(31 \%)$ from $20-24$ year, $16(5 \%)$ of them 15-19 years and 78(24.2\%) of them $30-49$ years.

Concerning Religion about 166(51.4\%) Protestant followed by 121 (37.5) Orthodox, 30 (9.3\%), Muslim and $6(1.9 \%)$ of them others. Regarding educational status of the respondents about 62 (19.2) were Primary school, 47 $(14.6 \%)$ were junior secondary school, 69 (21.4) high school level, 79 (24.5\%) were college education and above, and 66 $(20.4 \%)$ were unable to read and write. As to marital status of respondents about 290 (89.8\%) were married, 4(1.2\%) were single, $4(1.2 \%)$ were Widowed and 25 (7.7\%) were Divorced.

Regarding occupational status of mothers 169 (51.7\%) were House wife, 105 (32.5\%) were Self employee, 37 (11.5\%) Government employee,7 (2.2\%) students and 7 (2.2\%) private employee. Most of mothers live in Urban $254(78.6 \%)$ Among respondents who were married the educational status of their husband unable to read and write about $21(6.5 \%)$ were, about $29(9 \%)$ were primary school, about 27(8.4\%) Junior Secondary school and about $156(48.3 \%)$ attended College and above. As to occupation of their husband $137(42.4 \%)$ were self-employed,57(17.6\%) private employee and $129(39.9 \%)$ were Governmental employee.

Regarding average of monthly income 24 (7.4\%) of the Respondents had monthly income of $\leq 500$ ETB, 92 (28.5\%) of the Respondents 501-1500, while majority of the respondents 112 (34.7\%). Have monthly income between 1501-2500 ETB and 95 (29.4\%) of respondents earned more than 2500 ETB per month, all the details described in Table 1. 


\begin{tabular}{|c|c|c|}
\hline Characteristics & Frequency $(n=)$ & Percent \\
\hline \multicolumn{3}{|c|}{ Age in years } \\
\hline $15-19$ & 16 & $5 \%$ \\
\hline $20-24$ & 100 & $31 \%$ \\
\hline $25-29$ & 129 & $39.9 \%$ \\
\hline $30-34$ & 50 & $15.5 \%$ \\
\hline $35-49$ & 28 & $8.7 \%$ \\
\hline \multicolumn{3}{|c|}{ Marital status } \\
\hline Single & 4 & $1.2 \%$ \\
\hline Married & 290 & $89.8 \%$ \\
\hline Divorced & 25 & $7.7 \%$ \\
\hline Widowed & 4 & $1.2 \%$ \\
\hline \multicolumn{3}{|c|}{ Address } \\
\hline Urban & 254 & $78.6 \%$ \\
\hline Rural & 69 & $21.4 \%$ \\
\hline Total & $323 \mathrm{~s}$ & $100 \%$ \\
\hline \multicolumn{3}{|c|}{ Educational status } \\
\hline unable to read and write & 66 & $20.4 \%$ \\
\hline Primary education (1-6th) & 62 & $19.2 \%$ \\
\hline Junior Secondary education (7th-8th) & 47 & $14.6 \%$ \\
\hline High school education (9th-12th) & 69 & $21.4 \%$ \\
\hline college education (Diploma and above) & 79 & $24.5 \%$ \\
\hline \multicolumn{3}{|c|}{ Occupation } \\
\hline House wife & 169 & $51.7 \%$ \\
\hline Self-employed & 105 & $32.5 \%$ \\
\hline Government employee & 37 & \\
\hline Student & 7 & $2.2 \%$ \\
\hline Private employee & 7 & $2.2 \%$ \\
\hline \multicolumn{3}{|c|}{ Religion } \\
\hline Muslim & 30 & $9.3 \%$ \\
\hline Orthodox & 121 & $37.5 \%$ \\
\hline Protestant & 166 & $51.4 \%$ \\
\hline Others & 6 & $1.9 \%$ \\
\hline \multicolumn{3}{|c|}{ Educational status of husband } \\
\hline unable to read and write & 21 & $6.5 \%$ \\
\hline Primary education (1-6th) & 29 & $9 \%$ \\
\hline Junior Secondary education (7th-8th) & 27 & $8.4 \%$ \\
\hline High school education (9th-12th) & 90 & $27.9 \%$ \\
\hline college education (Diploma and above) & 156 & $48.3 \%$ \\
\hline \multicolumn{3}{|c|}{ Occupation of husband } \\
\hline
\end{tabular}




\begin{tabular}{|c|c|c|}
\hline Private employee & 57 & $17.6 \%$ \\
\hline Self-employed & 137 & $42.4 \%$ \\
\hline Government employee & 129 & $39.9 \%$ \\
\hline Average monthly Income & & \\
\hline$<500 \mathrm{ETB}$ & 24 & $7.4 \%$ \\
\hline $501-1500 \mathrm{ETB}$ & 92 & $28.5 \%$ \\
\hline $1501-2500 \mathrm{ETB}$ & 112 & $34.7 \%$ \\
\hline$>2501 \mathrm{ETB}$ & 95 & $29.4 \%$ \\
\hline
\end{tabular}

Table 1: Socio-Demographics characteristics of mothers attending PNC service Ambo health center and Awaro Health Center, November 2017 to January 2018.

The results indicated that among the interviewed women $289(89.4 \%)$ had attended antenatal care service. while 34(10.6\%) never attended ANC service.

From those who had attended the ANC service, $138(47.8 \%)$ had attended less than three times while $151(52.2 \%)$ had attended three times and above. About $222(68.7 \%)$ of the mothers had heard about postnatal care service and $101(31.3 \%)$ of the mothers never had heard. Among those respondents 93(28.8\%) heard about PNC from Health institution, 63(19.5\%) from Radio/TV, and 66(20.4\%) of them from Health Extension workers. From those mothers who had heard about postnatal care service, they knew about the kinds of services such as breastfeeding, family planning, immunization, counseling service and physical examination. Mothers about 18 (5.6\%) had positive attitudes towards to postnatal care services.

From the respondents all mothers who gave birth at health institution, 266(82.4\%) got PNC within 6hrs of their delivery, but $57(17.6 \%)$ who had birth at Home didn't get PNC service, 47(16.1\%) mothers got PNC within 1-2 days after birth, about 27(9.3\%) got PNC within 6 days and $217(74.6 \%)$ got PNC within 6 weeks of delivery.

From those who gave birth at health institution (266 mothers), 114(35.2\%) visited health institutions for PNC service only one time, but $14(1.2 \%)$ mothers have visited three times.

Regarding service provided under PNC, 103(31.9\%) of mothers responded that they have Immunized their infants, $19(5.8 \%)$ their infants got Physical examination, while $100(31 \%)$ mothers responded that they have gotten Family planning awareness.

From the total of 323 participants 57 (18\%) did not attend the postnatal care service. Regarding those none attended mothers the reasons for not attending PNC during their recent delivery were as follows: I don't see any need to attend 51(15.8\%), while $117(36.2 \%)$ I and my baby felt well or apparently healthy and $100(31 \%)$ lack of awareness (Table 2).

\begin{tabular}{|c|c|c|}
\hline Characteristics & Frequency & Percent \\
\hline ANC Visit & & \\
\hline Not used & 34 & $10.60 \%$ \\
\hline Once & 21 & $6.50 \%$ \\
\hline Twice & 117 & $36.20 \%$ \\
\hline Three and above & 151 & $46.70 \%$ \\
\hline Postnatal service for your last child & & \\
\hline Within 6 hrs. of delivery & 266 & $82 \%$ \\
\hline Within 1-2 days of delivery & 47 & $16.10 \%$ \\
\hline At 6 day of delivery & 27 & $9.30 \%$ \\
\hline
\end{tabular}




\begin{tabular}{|c|c|c|}
\hline Within 6 weeks of delivery & 217 & $74.60 \%$ \\
\hline $\begin{array}{c}\text { Subsequent postnatal Visit excluding your 1st } \\
\text { contact }\end{array}$ & & \\
\hline Not attended & 57 & $18 \%$ \\
\hline One time only & 114 & 35.2 \\
\hline Twice & 26 & $8 \%$ \\
\hline Three times and above & 14 & $1.20 \%$ \\
\hline
\end{tabular}

Table 2: Reproductive Health related Information of respondents of mothers attending at Ambo health center and Awaro Health center, November 2017 to January 2018.

\begin{tabular}{|c|c|c|}
\hline Health education given during ANC Visit & & \\
\hline On importance of ANC and PNC & 18 & $5.6 \%$ \\
\hline On importance of health facility delivery & 101 & $31.3 \%$ \\
\hline On importance of breastfeeding & 7 & $2.2 \%$ \\
\hline On importance of immunization & 62 & $19.2 \%$ \\
\hline On personal hygiene & 10 & $3.1 \%$ \\
\hline Not given & 125 & $38.6 \%$ \\
\hline \multicolumn{3}{|l|}{ Knowledge about PNC } \\
\hline Yes & 222 & $68.7 \%$ \\
\hline No & 101 & $31.3 \%$ \\
\hline \multicolumn{3}{|l|}{ If yes from were got information } \\
\hline Health institution & 93 & $28.8 \%$ \\
\hline Radio/TV & 63 & $19.5 \%$ \\
\hline Health extension workers & 66 & $20.4 \%$ \\
\hline \multicolumn{3}{|l|}{ Service included under PNC } \\
\hline Family planning & 100 & $31 \%$ \\
\hline Immunization for infant & 103 & $31.9 \%$ \\
\hline Physical examination & 17 & $5.3 \%$ \\
\hline I did not know & 101 & $31.3 \%$ \\
\hline \multicolumn{3}{|l|}{ Reason for PNC attendance } \\
\hline Excessive vaginal bleeding & 4 & $1.2 \%$ \\
\hline Physical examination & 6 & $1.9 \%$ \\
\hline Baby growth monitoring & 10 & $3.1 \%$ \\
\hline Baby need immunization & 217 & $67.1 \%$ \\
\hline BP Checks & 2 & $0.6 \%$ \\
\hline To start FP & 84 & $26 \%$ \\
\hline Previous PNC Attendance ( ) & & \\
\hline
\end{tabular}




\begin{tabular}{|c|c|c|}
\hline Yes & 55 & $17 \%$ \\
\hline No & 268 & $83 \%$ \\
\hline If no reasons for not getting PNC & & \\
\hline I did not see any need to attend & 51 & $15.8 \%$ \\
\hline I and my child felt well & 117 & $36.2 \%$ \\
\hline Lack of awareness & 100 & $31 \%$ \\
\hline
\end{tabular}

Table 3: Health education results.

The results indicate that among the interviewed women about $57(17.6 \%)$ given birth at Home, about $4(1.2 \%)$ were given birth at private clinic and the majority of the mothers̀ about 155(48\%) were given birth at Health center, followed by about 107(33.1\%) were given births at Hospital (Pie chart 1).

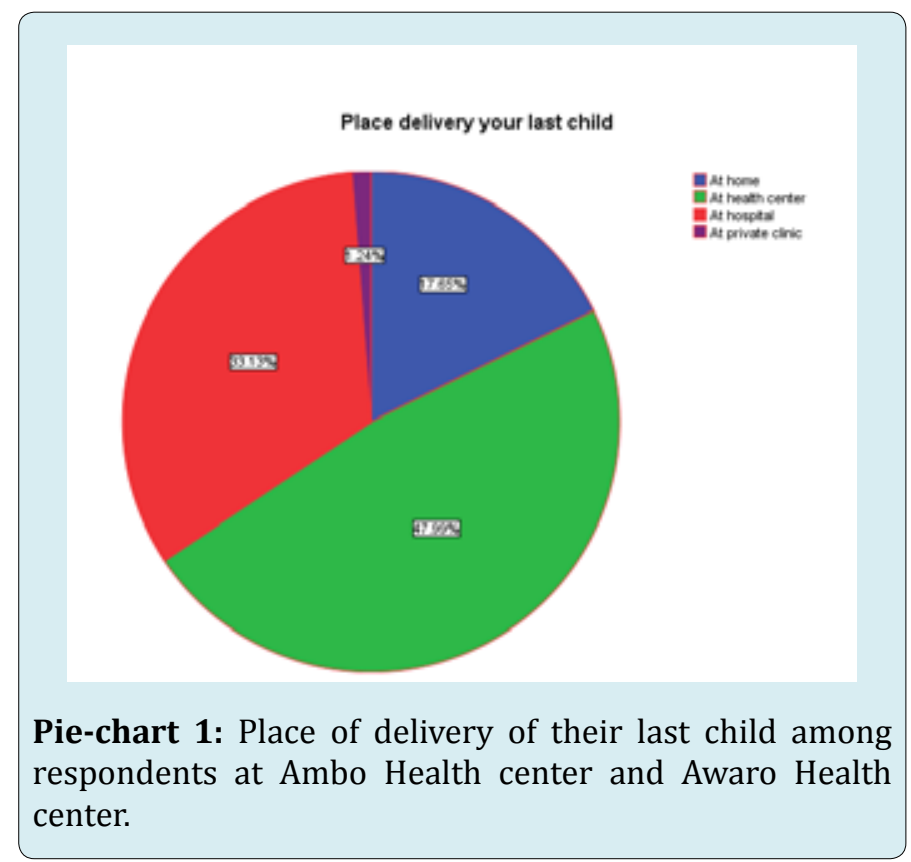

\section{Discussion}

This community based cross-sectional study tried to assess the utilization of postnatal care and associated factors among women who gave birth in the last year in Ambo town, Oromia Regional State. This study revealed that majority of the respondents 266 (82.4\%) delivered at health facilities, 57 (17.6\%) of mothers gave delivery at home. Regarding PNC utilization from all mothers who delivered at health facility 266(82.4\%) obtained PNC services. Based on this idea we identified mothers, who received and do not received PNC services to relate with $\mathrm{WHO}$ recommendation. Therefore, the result showed that among the 323respondents, 108 (33.4\%) utilized PNC services and 215 (66.6\%) of mothers did not received the PNC services.

According to this study the utilization of postnatal care service which higher than the study previously done in Sidama zone (southern Ethiopia) by Regassa (37.2\% of utilization) [9], similar studies done in Uganda (58 \%) [10] and Palestine (36.6\%) [11]. The difference might be cultural, religion, geographical, economical and the nature of study. The national coverage of PNC service in Ethiopia was 34.3 $\%$ which is almost similar with this study and, in the case of Amhara region $45.9 \%$, which was higher than from the present finding. The difference may be attributed to time, place, study design and social context variation between the present study and previous studies. This study identified the following factors as having an important influence on the utilization of postnatal care service. Age of the mother, husband's occupation, attendance of ANC service, household income, and decision making power of the women were found to be associated factors. Similarly different studies showed that among different factors affecting utilization of postnatal care services are educational level, occupational status, husbands' occupation, and awareness of postnatal care services, attendance of antenatal care service were the associated factors. Education is important to enhance female's autonomy so that women develop greater confidence and capabilities to make decisions regarding their own health. Many findings indicate that occupation of the mother is an important predictor for the utilization of PNC services. The analysis revealed that husband's occupation has a significant association with postnatal care utilization, showing the higher utilization of PNC services by the respondents having an educated and employed husbands.

Regarding to those respondent mothers who did not attend PNC services as indicated by the respondents and focus group discussion participants the most frequently raised reasons for not attending PNC services were lack of awareness, believing that the treatments were not important unless mothers or the new born baby felt sick, and I did not to see any need to attend. Another important factor which was mentioned in the focus group discussion (FGD) 
was that there is inappropriate health education by health professionals during ANC visit concerning PNC services. Most mothers assuming that the PNC services would be started on $45^{\text {th }}$ days after delivery especially for immunization and family planning services. The other important reason which was indicated by Focus group discussion participants and by the individual respondent mothers was lack of willingness and unfriendly approach by some health professionals in rendering appropriate maternal health service including ANC, an PNC services that may lead mothers not to attend PNC services even if the services were available.

\section{Limitations}

This study was utilized only a quantitative method, but lacks qualitative which is crucial to discover in-deepness view about the contributing factors. From the nature of cross-sectional study, it is unable to correctly demonstrate the way of relationship or association.

\section{Conclusion and Recommendation}

This study revealed that utilization of PNC in Ambo town is low compared with other studies previously done in Ethiopia. To increase utilization of PNC coverage and reduce maternal and neonatal mortality, mothers should obtain more appropriate education and quality ANC, delivery and PNC services. The results of this study might be useful for health professionals and health sector managers to develop appropriate strategies to improve utilization of PNC as well as ANC services.

\section{Conflict of Interests}

The authors declared that there are no competing interests.

\section{Acknowledgement}

Ambo University, College of Medicine and Health Sciences should be acknowledged for supporting financially to carry out this research. We also like to thank Ambo and Awaro Health centers' managers and all staff members. At last but not least, our grateful goes to the respondents who participated in this particular study.

\section{References}

1. Mesganaw F, abubeker K, Assefa M, Dinsa A, Daniel M, et al. (2000) Assessment of antenatal care services in rural training health centre in North West Ethiopia. Ethiop J Health Dev 14: 2.

2. World Health Organization (2004) Making pregnancy safer initiative.

3. World Health Organization (2003) Magnitude of Reproductive health problems.

4. Lumbiganon $\mathrm{P}$, Winiyakul N, Chongsomchai C, Chaisiti K (2004) From research to practice: the example of ANC \& PNC in Thailand. Bulletin of WHO 82(10): 746-749

5. Maharjan M, Singn B (2017) Knowledge regarding PNC among postnatal mothers: A Hospital based study. February

6. Ali MK, Wuleta B, Samuel Y, Hibret A, Mary C, et al. (2010) Programmatic correlates of maternal health care seeking behaviors in Ethiopia. Ethiopian Journal of Health Development 24(1): 92-99.

7. Mrisho M, Obrist B, Schellenberg JA, Haws RA, Kmushi AK, et al. (2009) The use of antenatal and postnatal care: perspectives and experiences of women and health care providers in rural southern Tanzania. BMC Pregnancy Childbirth 9: 10.

8. Dawidowicz A, Krajewska K, Kulak K, Kulikowski E, Perlowska MS, et al. (2003) Women's knowledge of health behaviors in the puerperium. Wiadomoscilekarskie (Warsaw, Poland: 1960) 57: 70-73.

9. Regassa N, (2011) Antenatal and postnatal care service utilization in Southern Ethiopia: A population based study. African Health Sciences 11: 390-397.

10. Nankwanga A (2004) Factors influencing utilisation of postnatal services in Mulago and MengoHospitals [master thesis], Kampala. Uganda: University of the Western Cape.

11. Dhaher E, Mikolajczyk RT, Maxwell AE, Kramer A (2008) Factors associated with lack of postnatal care among Palestinian women: A cross-sectional study of three clinics in the West Bank. BMC Pregnancy and Childbirth 8(26): $1-9$. 